\title{
BUDAYA LEMBAGA PENDIDIKAN SEBAGAI PILAR UTAMA MELAWAN DEGRADASI MORAL
}

\author{
Siti Alia', Nina Resma ${ }^{2}$, Ridwan Nurali ${ }^{3}$, Sugiwa Adi R ${ }^{4}$, Tegar Hamara ${ }^{5}$ \\ 1Prodi Administrasi Publik, UIN Sunan Gunung Djati Bandung \\ 2,3,4,5Prodi Ilmu Politik, UIN Sunan Gunung Djati Bandung \\ E-mail: aliaalya267@uinsgd.ac.id
}

\begin{abstract}
Moral is a provision for self-development. Problems that often occur in morals are problems that concern humans everywhere, both in developed societies and in societies that are still left behind. It is because one's moral depravity disturbs the peace of another. If in society many people are morally corrupted, it will cause damage to the community itself. Moral education for children can change children's behavior, so that when adults are more responsible and respectful of others so that they are able to face the challenges of the times .. Increasing moral considerations in children designed through school education, can help shape children's personalities, because with the formation of moral considerations. Using qualitative methods and theory from Durkheim, there are three elements to being a moral person. The first is discipline; second is attachment to the group; third is autonomy. These three elements are needed by every individual to become a moral person. This research results that these three elements provide a big role for moral development, especially when applied to a level of education such as in educational institutions.
\end{abstract}

Keywords: Education, Morals, Educational Institutions

\begin{abstract}
ABSTRAK
Moral merupakan bekal dalam mengembangkan diri. Masalah yang Sering terjadi pada moral adalah masalah yang menjadi perhatian manusia di mana saja, baik dalam masyarakat yang telah maju, maupun dalam masyarakat yang masih tertinggal. Hal itu disebabkan karena kerusakan moral seseorang mengganggu ketenangan yang lain. Jika dalam masyarakat banyak orang yang rusak moralnya, maka akan terjadinya kerusakan yang terjadi pada masyarakat itu sendiri. Pendidikan moral bagi anak dapat mengubah perilaku anak, sehingga jika sudah dewasa lebih bertanggung jawab dan menghargai sesamanya hingga mampu menghadapi tantangan jaman.. Peningkatan pertimbangan moral pada diri anak yang dirancang melalui pendidikan di sekolah, dapat membantu pembentukan kepribadian anak, karena dengan terbentuknya pertimbangan moral. Menggunakan metode kualitatif serta teori dari Durkheim ada tiga unsur untuk bisa menjadi pribadi yang bermoral yang pertama adalah disiplin; kedua adalah keterikatan pada kelompok; ketiga adalah otonomi. Ketiga unsur ini dibutuhkan setiap individu untuk bisa menjadi pribadi yang bermoral. Penelian ini menghasilkan bahwa ketiga unsur tersebut memberikan peran besar bagi perkembangan moral terutama apabila diterapkan pada suatu jenjang Pendidikan seperti di Lembaga pendidikan.
\end{abstract}

Kata kunci: Pendidikan, Moral, Lembaga Pendidikan

\section{PENDAHULUAN}

Dunia pendidikan adalah salah satu cara kita dalam melakukan transmisi ataupun transformasi dalam bentuk nilai maupun ilmu pengetahuan (Sudrajat, 2011). Oleh karena itu, peran dunia pendidikan sangatlah penting untuk menanamkan dan juga mengembangkan karakter bangsa ini. Terutama

* Copyright (c) 2020 Siti Alia et.all

This work is licensed under a Creative Commons Attribution-ShareAlike 4.0 International License. 
pendidikan karakter yang berperan dalam kehidupan manusia, bukan hanya dalam bentuk pengetahuan moral terapi juga dalam bentuk tindakan moral. Namun yang terjadi belakangan ini masyarakat mengalami degradasi moral yang cukup serius (Sari, 2019; Setyoningsih, 2018). Maraknya perilaku manipulatif, korupsi, pornografi dan pelanggaran-pealanggaran lainnya seperti pelanggaran norma agama, budaya, adat dan etika kemanusiaan merupakan bukti dari degradasi moral yang meningkat dari tahun ke tahun.

KPK (2018) mencatatkan bahwa sejak tahun 2004 - 2018 untuk kasus korupsi selalu mengalami kenaikan. Dilihat dari tindakan eksukusi dari tahun 2017 yang mencapai 83 eksekusi menjadi 113 eksekusi di tahun 2018. Selain itu jumlah kejahatan yang terjadi cukup banyak dan terjadi peningkatan hal itu dapat dilihat pada laporan BPS (2019) serta pada gambar 1. Peningkatan hal ini disinyalir karena turunnya pemahaman seseorang tentang moral, dimana seseorang tidak merasakan ketakutan bahkan kecemasan dalam melakukan tindak kejahatan, hal ini bisa diharapkan bisa rubah dengan Pendidikan sejak dini yaitu sejak di bangku sekolah. Dimana Pendidikan moral dijadikan hal penting diantara pelajaran lainnya.

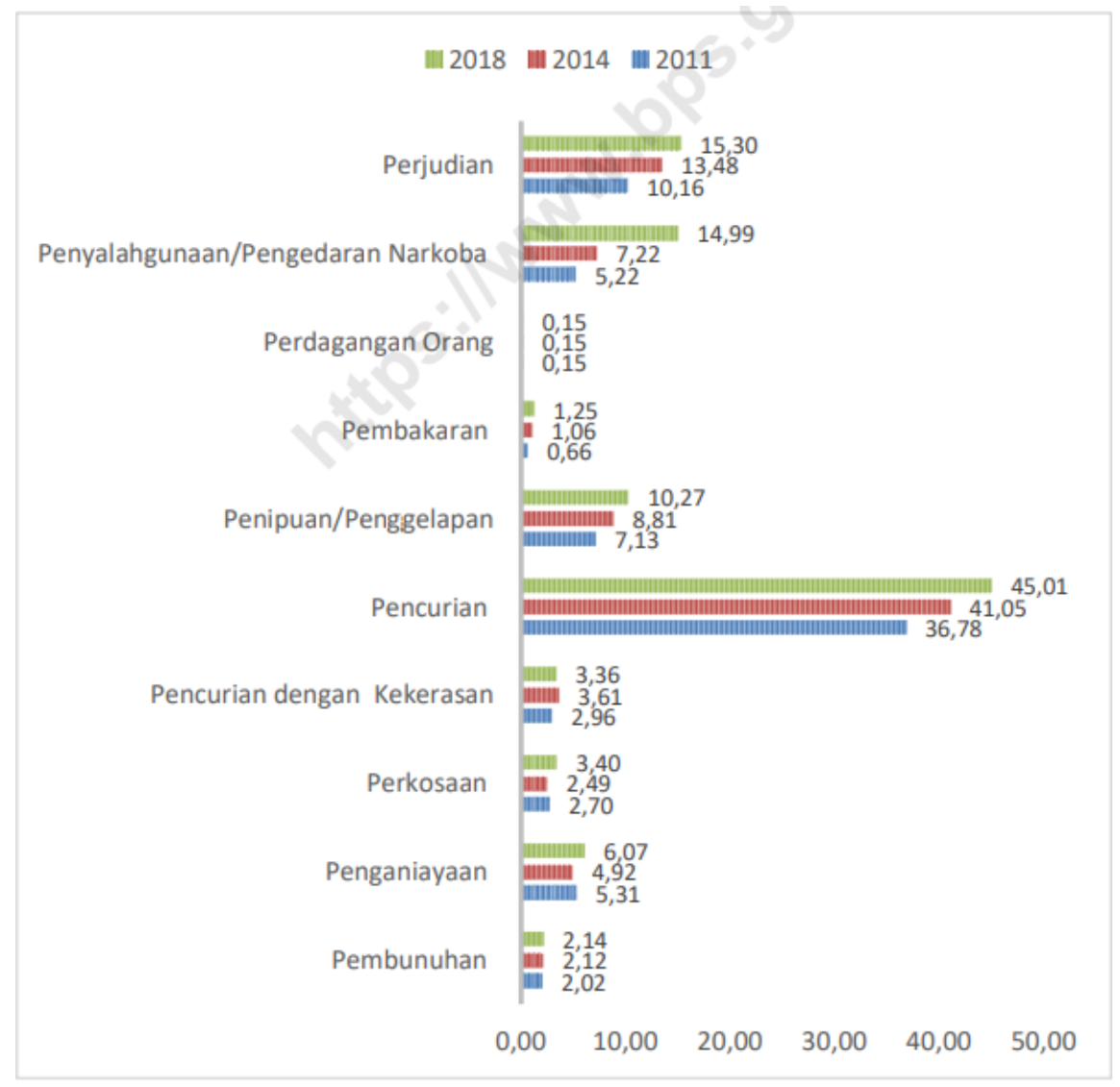

\section{Gambar 1. Jumlah Desa/Kelurahan yang Ada Kejadian Kejahatan Selama Setahun terakhir menurut jenis kejahatan, 2011,2014,2018}

Penelitian terdahulu tentang degradasi moral diteliti oleh Muthohar (2016) tentang mencari antisipasi degradasi moral di era global yang menghasilkan pembimbingan problem solving dalam menghadapi persoalan diri dan masyarakatnya serta pembentukan pemahaman secara integral tentang 
hubungannya dengan Allah dan Jahroh \& Sutarna (2016) mengenai Pendidikan karakter sebagai upaya mengatasi degradasi moral yang menghasilkan Pendidikan karakter harus diupayakan dan diajarkan sedini mungkin. Pada artikel ini peneliti , melihat dari sudut pandang yang berbeda, dimana artikel ini akan melihat peran Lembaga Pendidikan serta menggunakan teori dari Durkheim (2012). Yang bertujuan untuk merumuskan bagaimana Lembaga Pendidikan dapat melawan degradasi moral yang selalu meningkat dari waktu ke waktu.

Dari data yang dipaparkan di atas mengenai pengamatan tentang degradasi moral, degradasi moral kita dalam bertoleransi mempunyai presentasi tertinggi yang harus dibenahi. Artikel ini juga untuk menyadarkan kita akan pentingnya moral atau pendidikan karakter yang saat ini sangat memprihatinkan sehingga dapat menekan tingkat pelanggaran baik dalam bentuk norma agama, budaya, adat maupun etika kemanusiaan dan juga menjadikan masyarakat yang bermoral.

\section{METODE PENELITIAN}

Metode penelitian yang digunakan dalam penelitian ini adalah metode analisis deskriptif kualitatif dan prosedur analisis data kualitatif yaitu mengumpulkan data-data yang berasal beberapa jurnal penelitian yang difokuskan pada topik penelitian (Yusuf, 2016). Keberhasilan penelitian keilmuan dapat ditentukan dengan keabsahan data dan cara yang dipakai dalam penelitian tersebut. Beberapa metode yang kami gunakan adalah menggunakan penelitian literatur dan menggunakan pendekatan kualitatif deskriptif yang berupa pencarian masalah dan pengembangan secara terperinci pada kejadian tertentu melalui hasil riset atau teori yang berdasarkan kajian analisis filosofis. Teknik pengumpulan data yang digunakan merupakan teknik pengumpulan data sekunder yang mana data dapat dikutip atau diperoleh dari beberapa sumber melalui hasil penelitian, jurnal, artikel, dan dokumen lainnya yang berkaitan tentang penelitian ini.

\section{HASIL DAN PEMBAHASAN}

\section{Pengertian Pendidikan}

Menurut Djamaluddin (2014) menjelaskan bahwa pendidikan adalah upaya manusia sebagai bentuk pengembangan diri baik itu dalam mengembangkan potensi diri, pengetahuan, jasmanai serta rohahi yang mana diharapkan mengikuti nilai - nilai yang ada pada masyarakat baik itu norma maupun budaya yang sudah ada sebelumnya.. Usaha-usaha tersebut dilakukan untuk menanamkan nilai-nilai dan norma-norma serta mengembangkan potensi-potensi baik jasmani maupun rohani untuk diwariskan kepada generasi selanjutnya. Prof. H. Mahmud Yunus dalam Satrawijaya (Satrawijaya, 2019) yang dimaksud dengan pendidikan adalah suatu usaha yang dipilih dengan tujuan meningkatkan ilmu pengetahuan, akhlak dan jasmani agar mendapatkan tujuan mereka dan juga memperoleh kehidupan yang bahagia dan apa yang dilakukannya dapat bermanfaat bagi dirinya dan masyarakat, agama serta bangsa dan negara. Pendidikan merupakan sebuah batu loncatan untuk menggapai suatu tujuan dengan cara belajar sesuatu memperkaya diri dari yang sebelumnya tidak tahu menjadi tahu, serta memperkuat metal dan moral agar tidak terjerumus kedalam kesalahan baik kesalahan dalam adat istiadat, agama dan hukum yang berlaku. 


\section{Pengertian Moral}

Moral awal nya disebut juga mores, mores didalam Bahasa latin disebut juga kebiasaan, cara hidup dan adat istiadat. Mores sendiri dapat dikatakan juga sebagai manner atau sikap yang ditunjukkan. Di lihat lebih jauh pada Indonesia moral dapat dikatakan juga sebagai akhlak yaitu sebagai pedoman bagi kita manusia untuk mendefenisikan suatu prilaku yang baik dan berdasarkan nilai - nilai, norman dan budaya yang ada dimasyarakat (Andayani, 2016). Moral dapat dikaitkan pula dengan Etika dimana moral lebih kepada suatu perbuatan yang telah diterima oleh umum sedangkan etika adalah suatu perbuatan yang mengikuti prinsip - prinsip tertentu. yang dibuat dan kembangkan bagi suatu profesi (Sudaryanti, 2012). Moral sangat berkaitan dengan budaya dimana moral sendiri bisa berasal dari sebuat wejangan-wejangan, kumpulan peraturan lisan serta patotkan yang sudah ada sebelumnya. (Endah, 2018). Dapat disimpulankan moral merupakan suatu bentuk ukuran bagi seseorang menilai prilaku manusia.

\section{Pentingnya Pedidikan Moral}

Dalam suatu bangsa dapat dilihat baik buruknya dari moral pemudanya. Apabila moral pemudanya itu baik, maka baiklah kondisi bangsa tersebut. Sebaliknya, apabila kondisi moral pemudanya rusak, maka rusaklah kondisi bangsa tersebut. Para pemuda lah yang akan melanjutkan perjuangan generasi terdahulu. Amanah yang besar ada pada pundak mereka (Sinulingga, 2016). Untuk mempersiapkan generasi yang mampu mengemban tanggung jawab bangsa, maka pendidikanlah yang berperan dalam menggembleng para generasi penerus agar siap membawa bangsa ini menjadi lebih baik dan mampu mengahadapi tantangan era globalisasi dan modernisasi baik itu melalui pendidikan formal maupun non formal

Kajian tentang moral menjadi salah satu focus kajian menarik di seluruh dunia khususnya di Indonesia, moral bisa juga suatu bentuk karakter yang dapat menentukan nasib suatu negara. Semakin Pendidikan moral diabaikan akan membuat meningkat nya perbuatan - perbuatan tercela yang tidak sesuai norma dan hukum yang ada, didunia indutri juga dituntut untuk mempunyai suatu moral yang baik, suatu kepribadian yang dapat menunjang kinerja pegawai dapat berasal dari budaya kerja yang baik atau bahkan sistem rekrutmen yang benar. Pendidian moral sudah mulai terabaikan dapat dilihat dengan tingginya kasus-kasus keekerasan serta penipuan dan masih banyaknya anak-anak yang belum mengetahui pentingnya moral bagi mereka kelas dimasa yang akan datang (Damanik, 2019). Indonesia dengan karakter budaya yang cukup religious yang mana mayoritas masyarakat nya mempunya agama dan kepercayaan masing sudah seharusnya negara yang beragama mempunyai masyarakat yang bermoral baik, karena setiap agama selalu mengajarkan berbuat hal yang benar sesuai norma dan nilai yang berlaku (Andayani, 2016). Selain Pendidikan agama ada hal lain yang dapat menjaga dan menumbuhkan moral bagi manusia yaitu pada jenjang Pendidikan khusus setiap Lembaga Pendidikan yang sebaiknya memiliki salah satu tujuan menciptakan manusia yang bermoral baik dan memiliki keinginan kuat untuk menolong sesama.

\section{Budaya Lembaga Pendidikan dalam mengatasi degradasi moral}

Budaya salah satu cara yang dapat mengatasi degradasi moral, ini dilihat dari prilaku masyarakat Indonesia yang majemuk dan memiliki keberagaman akan sulit apabila hanya dibuatkan aturan pada sebuah undang - undang ataupun peraturan semata. Masyarakat Indonesia khusus nya pelajar Indonesia masih sangat terpengaruh terhadapat lingkungkan sekitar dalam berprilaku baik itu lingkungan sekolah maupun lingkung keluarga.

Menurut Durkheim (2012) ada 3 hal yang harus diikuti dalam memperkuat budaya yang baik yaitu pertama disiplin, Lembaga Pendidikan mempunyai peran penting dalam unsur ini karena disekolah, universitas 
dan Lembaga Pendidikan mempunyai kuasa untuk membuat suatu peraturan serta mempunyai suatu kekuasaan untuk membuat peraturan itu menjadi budaya, dimana peserta didik biasanya lebih terdorong mengikuti peraturan disekolah dari pada aturan - aturan yang ada dilingkungan rumahnya. Kedua. Keterikatan pada kelompok, maksudnya disini adalah pengelompokkan peserta didik dengan baik dan benar akan membentuk suatu komunitas yang baik pula hal ini dapat dilakukan Lembaga Pendidikan dengan mendirikan unit kerja mahasiswa, unit kerja siswa dan organisasi lainnya yang dapat membuat berbagai kegiatan positive dalam menghabiskan waktunya di luar jam pelajaran salah satunya bisa dengan mengeluarkan peraturan bahwa setiap peserta didik wajib setidaknya mengikuti satu unit kegiatan yang ada pada Lembaga Pendidikan tersebut. Dan terakhir otonomi yaitu keputusan pada diri sendiri, unsur ini menjadi penentu nantinya luaran dari Lembaga Pendidikan merupakan hal baik atau kurang baik, pada unsur ini pusat konseling dan pusat karir menjadi peran utama dalam menimbulkan sikap dan karakter diri peserta didik agar mempunyai moral yang baik, dengan pengarahan dari tim pusat karir dan konseling peserta didik diharapkan dapat pengarahan yang jelas akan rencana 5 - 10 tahun kedepan dimana dengan perencanaan yang baik akan meningkatkan kepercayaan diri serta menjaga peserta didik tidak salah memilih jalan untuk masa depannya.

\section{SIMPULAN}

Pendidikan moral merupakan suatu proses penting dalam kehidupan yang mana jadi patokan atau wejangan baik buruknya suatu bangsa. Keadaan pendidikan moral kita saat ini telah mengalami degradasi yang sangat memprihatinkan seperti yang telah dipaparkan di pendahuluan. Peran Lembaga Pendidikan sangat penting untuk melawan degradasi moral, dengan diterapkannya tiga unsur dari Durkheim akan meningkatkan peluang luaran lembaga pendidikan dapat bersaing secara baik dimasyarakat serta tidak terjerumus kedalam kegiatan tidak bermoral.

\section{DAFTAR PUSTAKA}

Andayani, D. (2016). Relasi Etika Kerja dan Etos Kerja dalam Islam. INOVATIF: Jurnal Penelitian Pendidikan, Agama Dan Kebudayaan, 2(2), 112-152.

BPS. (2019). Statistik Kriminal 2019. Retrieved from https://www.bps.go.id/publication/2019/12/12/66c0114edb7517a33063871f/statistik -kriminal-2019.html

Damanik, D. A. (2019). Kekerasan Dalam Dunia Pendidikan: Tinjauan Sosiologi Pendidikan. Jurnal Sosiologi Nusantara, 5(1), 77-90.

Djamaluddin, A. (2014). Filsafat Pendidikan. Istiqra: Jurnal Pendidikan Dan Pemikiran Islam, 1(2).

Durkheim, E. (2012). Moral education. Courier Corporation.

Endah, K. (2018). ETIKA PEMERINTAHAN DALAM PELAYANAN PUBLIK. Moderat: Jurnal Ilmiah Ilmu Pemerintahan, 4(1), 141-151.

Jahroh, W. S., \& Sutarna, N. (2016). Pendidikan Karakter Sebagai Upaya Mengatasi Degradasi Moral. Prosiding Seminar Nasional Inovasi Pendidikan, 395-402.

KPK. (2018). Rekapitulasi Tindak Pidana Korupsi. Retrieved May 1, 2020, from KPK.go.id website: https://acch.kpk.go.id/id/statistik/tindak-pidana-korupsi

Muthohar, S. (2016). Antisipasi degradasi moral di era global. Nadwa, 7(2), 321-334.

Sari, D. N. (2019). Upaya Preventif Guru Kristen dalam Menghadapi Degradasi Moral Anak. Visio Dei: Jurnal Teologi Kristen, 1(1), 79-100.

Satrawijaya, L. (2019). Peningkatan Prestasi Belajar Penjaskes Materi Bola Voli melalui Penggunaan Metode Pembelajaran Demonstrasi pada Siswa Kelas IV SDN 3 Padamara. EDISI, 1(2), 322336. 
Setyoningsih, Y. D. (2018). Tantangan Konselor di era milenial dalam mencegah degradasi moral remaja. Prosiding Seminar Nasional Bimbingan Dan Konseling, 2(1), 134-145.

Sinulingga, S. P. (2016). Teori Pendidikan Moral Menurut Emile Durkheim Relevansinya Bagi Pendidikan Moral Anak Di Indonesia. Jurnal Demo, 26(2), 214-248.

Sudaryanti, S. (2012). Pentingnya pendidikan karakter bagi anak usia dini. Jurnal Pendidikan Anak, $1(1)$.

Sudrajat, A. (2011). Mengapa pendidikan karakter? Jurnal Pendidikan Karakter, 1(1).

Yusuf, A. M. (2016). Metode penelitian kuantitatif, kualitatif \& penelitian gabungan. Prenada Media. 